\title{
ESTUDO DE CASO SOBRE AS CONDIÇÕES DE SEGURANÇA DOS FUNCIONÁRIOS DE BASE DA EMPRESA X NO MUNICÍPIO DE ANASTÁCIO/MS
}

A STUDY ABOUT SAFETY CONDITIONS OF BASE EMPLOYEES FROM COMPANY X IN ANASTÁCIO/MS DISTRICT

\author{
Osmar Souza Costa ${ }^{1}$ \\ Ricardo Lanzarini ${ }^{2}$
}

\section{Resumo:}

A presente pesquisa foi realizada em 2008 numa empresa revendedora de combustíveis para veículos automotores no município de Anastácio/MS. A metodologia é a pesquisa exploratória com estudo de caso e observação participante, objetivando conscientizar empresários e empregados sobre a importância da melhoria das condições de segurança do trabalho. Dentre os resultados, o risco de morte e contato com produtos químicos são problemas que trabalhadores da empresa investigada estão expostos diariamente na execução das tarefas. Para a adequação das atividades há necessidade da implantação de Normas de Segurança e Medicina do Trabalho, diminuindo os acidentes de trabalho e aumentando a produtividade.

Palavras-chave: Segurança; Trabalho; Saúde.

\begin{abstract}
:
This research was conducted in 2008 on a firm sale of fuel for motor vehicles in Anastácio/MS. The methodology adopted was the exploratory research and case study, with participant observation, aiming to educate business owners and employees about the importance of improving conditions of work safety in the sector. Among the findings, the risk of death and contact with chemicals are problems that the company's workers investigated are exposed daily in performing their tasks. For the appropriateness of the
\end{abstract}

\footnotetext{
${ }^{1}$ osmarsouzacosta10@hotmail.com. Brasil, Bacharel em Administração pela UFMS e especialista em Gestão de Recursos Humanos pela Edutec/UNINTER. Rua Estevão Alves Correa, 381. Centro. Cep: 79200-000 - Aquidauana - MS

2 ricardolanzarini@gmail.com. Brasil, Universidade Federal de Santa Catarina - UFSC. Av Eng. Agro. Andrey C. Ferreira, 27. CEP: 88040-535. Florianópolis - SC - Brasil.
}

Data da submissão: $25 / 06 / 2011$

Data da aprovação: 30/08/2011 
activities is needed to implement Safety Standards and Occupational Medicine, reducing accidents and increasing productivity.

Keywords: Security; Labor; Health.

\section{Introdução}

Esta pesquisa aborda as condições de trabalho e as relações entre empregado e empregador, bem como a importância da segurança do trabalho dos funcionários de uma determinada organização - identificada como Empresa $\mathrm{X}$-, com funcionários denominados "funcionários de base" e que trabalham diariamente com a revenda de combustíveis para veículos automotores, abastecimento, lavagem, lubrificação e troca de óleo, realizada no ano de 2008, no município de Anastácio/MS.

Procuramos responder ao seguinte questionamento: Quais as condições de segurança que se encontram os funcionários de base da Empresa X? Esta análise parte do pressuposto de Barbosa Filho (2001) ao enfatizar que donos de micro e pequenas empresas não dão a devida importância às condições de trabalho e segurança dos seus empregados por estarem atarefados e sobrecarregados com ações e decisões da empresa, além de não possuírem, em sua maioria, formação profissional adequada e submetem seus funcionários a condições inadequadas de segurança no trabalho.

Com objetivo de conscientizar empresários e empregados de micro e pequenas empresas a respeito da importância da melhoria nas condições de segurança do trabalho, a metodologia de pesquisa é exploratória, seguida de estudo de caso. Conforme Acevedo e Nohara (2004), a pesquisa exploratória é a primeira etapa de uma investigação maior que também abrangerá outros níveis de pesquisa e tem como objetivo proporcionar a melhor compreensão do fenômeno investigado por intermédio de levantamentos bibliográficos, coleta de dados e informações complementares em entidades, instituições ou pessoas ligadas ao assunto, permitindo que o pesquisador delineie precisamente as questões envolvidas. As informações contidas na pesquisa foram coletadas por meio da observação participante (RICHARDSON, 1999), com a realização de estágios acadêmicos na referida empresa, bem como pela aplicação de questionário fechado destinado aos 10 (dez) funcionários de base, que por ética profissional, mantêm-se 
anônimos. Os estágios supervisionados auxiliaram em larga escala para a observação e vivência cotidiana do lugar pesquisado e das funções comerciais desempenhadas.

Relacionamos, desse modo, as operações de base às Normas Regulamentadoras da Segurança e Medicina do Trabalho, instituídas e regidas pelo Ministério do Trabalho e Emprego (MTE), a fim de apontar à Empresa $\mathrm{X}$ suas falhas e riscos, bem como as medidas legais que devem ser adotadas para que se possa diminuir os riscos de acidentes de trabalho de modo preventivo.

\section{A segurança do trabalho}

Para que se possa compreender melhor a segurança no trabalho, é importante conhecer o significado das palavras; segurança e trabalho. Assim:

Trabalho é a aplicação das forças e faculdades humanas para alcançar um determinado fim. Atividade coordenada, de caráter físico e ou intelectual, necessária À realização de qualquer tarefa, serviço ou empreendimento; trabalho remunerado ou assalariado (FERREIRA, 2001, p.679). Segurança é o ato ou efeito de segurar é um estado, qualidade ou condição de seguro é você ter a certeza e a confiança em si mesmo (ibidem, p.627).

Segurança do trabalho consiste em um conjunto de ações preventivas que tem como principal objetivo evitar acidentes decorrentes do labor, preservando, assim, a saúde e o bem estar do trabalhador. A lei $\mathrm{n}^{\circ}$. 6.514, de 22 de dezembro de 1977, foi um grande marco na prevenção de acidentes de trabalho no Brasil, que por meio da portaria $\mathrm{n}^{\circ}$. 3.214, de 08 de junho de 1978, instituiu as Normas Regulamentadoras de Segurança e Medicina do Trabalho.

No Brasil, o órgão responsável por esta regulamentação é o Ministério do Trabalho e Emprego (MTE), cuja coordenação no âmbito nacional fica sobre responsabilidade da Secretaria de Saúde e Segurança do Trabalho e a fiscalização fica a cargo das Delegacias Regionais do Trabalho. Os artigos 154 a 223 do Título II, do capítulo V da Consolidação das Leis do Trabalho - CLT "Da Segurança e Medicina do Trabalho", regidos pela lei no. 6.514 de 22 de dezembro de 1977 tratam das questões referentes à segurança e higiene do 
trabalhador no seu local de trabalho e seu detalhamento e aplicações estão contidas em 33 Normas Regulamentadoras (NRs).

As Normas Regulamentadoras são de observância obrigatória pelas empresas públicas e privadas que possuem empregados regidos pela Consolidação das Leis do Trabalho e servem de recomendações técnicas com embasamento legal. Para o estudo de caso apresentado são trabalhadas 10 (dez) Normas de maneira mais abrangente, a saber: NR-01 - Disposições Gerais; NR-05 - Comissão Interna de Prevenção de Acidentes CIPA; NR-06 - Equipamentos de Proteção Individual - EPI; NR-09 - Programa de Prevenção de Riscos Ambientais; NR-15 - Atividades e Operações Insalubres; NR-16 Atividades e Operações Perigosas; NR-17 - Ergonomia; NR-20 - Líquidos Combustíveis e Inflamáveis; NR-23 - Proteção Contra Incêndios; NR-26 - Sinalização de Segurança; ambas correlatas às atividades desenvolvidas na Empresa X.

\section{NR-01 - Disposições Gerais}

São aplicadas Normas Regulamentadoras aos trabalhadores avulsos, às entidades ou empresas que lhes tomem o serviço e aos sindicatos que representem suas categorias profissionais. Considera-se, nesta perspectiva, que empregador é a empresa individual ou coletiva que admite, assalaria e dirige a prestação pessoal de serviços, equiparando-se ao empregador os profissionais liberais, as instituições de beneficência, as associações recreativas ou outras instituições sem fins lucrativos, que admitem trabalhadores como empregados; empregado é a pessoa física que presta serviços de natureza não eventual e mediante salário; empresa é o estabelecimento ou o conjunto de estabelecimentos, canteiros de obra, frente de trabalho, locais de trabalho e outras, que utiliza o empregador para atingir seus objetivos; e como local de trabalho a área onde são executados os trabalhos.

Com relação a Segurança e Medicina do Trabalho, cabe a empresa cumprir e fazer cumprir as disposições legais e regulamentares estabelecidas a fim de prevenir atos inseguros no desempenho do trabalho; divulgar as obrigações e proibições que os empregados devam conhecer e cumprir; dar conhecimento aos empregados de que serão 
passíveis de punição, pelo descumprimento das ordens de serviço expedidas; determinar os procedimentos que deverão ser adotados em caso de acidente do trabalho e doenças profissionais ou do trabalho; adotar medidas determinadas pelo MTE; e adotar medidas para eliminar ou neutralizar a insalubridade e as condições inseguras de trabalho.

A partir desses pressupostos, é dever e obrigação do empregador informar aos trabalhadores quanto os riscos profissionais que possam originar-se nos locais de trabalho; os meios para prevenir e limitar tais riscos e as medidas adotadas pela empresa; os resultados dos exames médicos e de exames complementares de diagnóstico aos quais os próprios trabalhadores forem submetidos; os resultados das avaliações ambientais realizadas nos locais de trabalho; bem como permitir que representantes dos trabalhadores acompanhem a fiscalização dos preceitos legais e regulamentares sobre segurança e medicina do trabalho. Assim, é dever dos empregados cumprir as disposições legais e regulamentares sobre segurança e medicina do trabalho, inclusive as ordens de serviço expedidas pelo empregador; usar o Equipamento de Proteção Individual (EPI) fornecido pelo empregador; submeter-se aos exames médicos previstos nas Normas Regulamentadoras e colaborar com a empresa para suas devidas aplicações.

\section{NR-05 - Comissão Interna de Prevenção de Acidentes de Trabalho (CIPA)}

A Comissão Interna de Prevenção de Acidentes de Trabalho (CIPA) é constituida de representantes dos empregados e empregadores, com objetivo de prevenir acidentes e doenças ocupacionais, zelar pelas boas condições de saúde e segurança no local de trabalho e melhorar o ambiente para os trabalalhadores. Deve ter sua organização obrigatória em qualquer local de trabalho que possua o número mínimo de 20 (vinte) trabalhadores regidos pela CLT.

Dentre suas atribuições identifica riscos do processo de trabalho, elabora planos de trabalho que possibilitem a ação preventiva para problemas de segurança e saúde no trabalho, participa da implementação e do controle da qualidade das medidas de prevenção necessárias, bem como da avaliação das prioridades de ação nos locais de trabalho. Divulga, ainda, aos trabalhadores, informações relativas à segurança e saúde no 
trabalho, participa das discussões promovidas pelo empregador para avaliar os impactos de alterações no ambiente e processo de trabalho relacionado à segurança e saúde dos trabalhadores. Promove o cumprimento das Normas Regulamentadoras, bem como cláusulas de acordos e convenções coletivas de trabalho. Participa também da análise das causas das doenças e acidentes de trabalho e propõe medidas de solução dos problemas identificados e promove anualmente a Semana Interna de Prevenção de Acidentes do Trabalho - SIPAT.

A empresa deverá promover treinamento para os membros da CIPA, titulares e suplentes, antes da posse. Para se conhecer o funcionamento de todo o processo ocorre um treinamento específico a respeito do ambiente e das condições de trabalho da referida empresa. Este treinamento deverá ser ministrado por um profissional da área de segurança, com a carga horária de 20 (vinte) horas realizado no expediente normal da empresa.

\section{NR-06 - Equipamento de Proteção Individual (EPI)}

Considera-se Equipamento de Proteção Individual (EPI) todo dispositivo ou produto, de uso individual utilizado pelo trabalhador, destinado à proteção, a segurança e a saúde no trabalho. A empresa é obrigada a fornecer aos empregados, gratuitamente o EPI adequado ao risco, em perfeito estado de conservação e funcionamento. A constante fiscalização e o uso dos equipamentos de proteção são importantes para o bom funcionamento da empresa, visto que empregados estarão seguros e a empresa ganha em confiabilidade e responsabilidade empresarial.

Dentre os equipamentos individuais de proteção utilizados por trabalhadores, temse capacete, utilizado para proteger a cabeça contra impactos de objetos sobre o crânio; proteção contra choques elétricos, queimaduras, respingos de ácidos ou líquidos quentes e químicos; proteção dos olhos e face, utilizados contra impactos de partículas, luminosidade intensa, radiação e respingos de produtos químicos; proteção respiratória e capuz de segurança para proteção do crânio e pescoço contra respingos de produtos químicos e respirador purificador de ar para proteção das vias respiratórias contra 
partículas e gases emanados de produtos químicos; proteção para membros superiores, como creme para as mãos contra produtos químicos; e EPI para membros inferiores, como calçados ou sapatos, botinas, botas e protetor do dorso do pé.

\section{NR-09 - Programa de Prevenção de Riscos Ambientais (PPRA)}

Seu objetivo é a de preservar a saúde e a integridade dos trabalhadores com avaliações e controles de ocorrências de riscos no ambiente de trabalho, estabelecendo a obrigatoriedade das empresas e instituições de elaborar e implementar o PPRA. Para Barbosa Filho (2001, p.52), "diariamente, o ambiente, as ferramentas, as máquinas e as posturas assumidas, entre outros variáveis presentes no ambiente de trabalho, nos colocam à mercê de oportunidades de danos a nossa integridade e a nossa saúde"

Na NR-09 são considerados riscos ambientais os agentes físicos, como ruídos, vibrações, pressões anormais, temperaturas extremas, radiações; químicos, a exemplo de substâncias, compostos ou produtos que possam penetrar no organismo pela via respiratória, nas formas de poeiras, fumos, névoas, neblinas, gases ou vapores, ou que, pela natureza da atividade de exposição, possam ter contato ou ser absorvido pelo organismo através da pele ou por ingestão; e biológicos existentes nos ambientes de trabalho capazes de causar danos à saúde do trabalhador, como bactérias, fungos, bacilos, parasitas, protozoários, vírus, entre outros.

\section{NR-15 - Atividades e Operações Insalubres}

São consideradas atividades ou operações insalubres aquelas que, por sua natureza, condição ou métodos de trabalho, expõe os empregados a agentes nocivos à saúde, visto que são facilmente encontrados, em alguns ambientes de trabalho, riscos freqüentes como ruído, conforto térmico e risco químico.

Entende-se por "Limite de Tolerância", para os fins desta Norma, a concentração ou intensidade máxima ou mínima, relacionada com a natureza e o tempo de exposição ao agente, que não causará dano à saúde do trabalhador, durante a sua vida laboral. $\mathrm{O}$ órgão que caracteriza as atividades e operações insalubres é o MTE. Caso haja reclassificação 
dos agentes lesivos à saúde, exterminando do quadro como agente nocivo, não será mais devido o adicional de insalubridade na proporção de 40\%, $20 \%$ e 10\%, segundo o grau de classificação de insalubridade; sem caber qualquer tipo de reclamação por parte do empregado fundamentando em direito adquirido e impossibilidade de redução salarial; poderá também deixar de existir o adicional se com a utilização de equipamentos de proteção diminui a agressividade do agente ao limite de tolerância, caso o empregador forneça os EPIs necessários, conforme a NR-6.

No caso de incidência de mais de um fator de insalubridade, será apenas considerado o de grau mais elevado, para efeito de acréscimo salarial, sendo vedada à percepção cumulativa. A eliminação ou neutralização da insalubridade determinará a cessação do pagamento do adicional respectivo, ficando a cargo de avaliação pericial por órgão competente, que comprove a inexistência de risco à saúde do trabalhador.

Com relação à saúde e bem estar físico, é fundamental que o local de trabalho seja um ambiente agradável e saudável, cabendo ao empregador oferecer boas condições aos seus empregados. A umidade, o calor e a falta de ventilação no local de trabalho são influenciados por fatores como: as vestimentas, a posição e a localização geográfica e as edificações, fatores estes que devem ser adequadamente supridos para que não traga prejuízo à saúde do trabalhador.

\section{NR-16 - Atividades e operações Perigosas}

O exercício de trabalho em condições de periculosidade assegura ao trabalhador a percepção de adicional de $30 \%$ (trinta por cento), incidente sobre o salário, sem os acréscimos resultantes de gratificações, prêmios ou participação nos lucros da empresa. $\mathrm{O}$ empregado poderá optar pelo adicional de insalubridade que porventura the seja devido.

São consideradas atividades ou operações perigosas as executadas com explosivos sujeitos a: degradação química ou autocatalítica e a ação de agentes exteriores, tais como, calor, umidade, faíscas, fogo, fenômenos sísmicos, choque e atritos, bem como o transporte de inflamáveis líquidos e gasosos liquefeitos em caminhão-tanque e nas operações em postos de serviço e bombas de abastecimento de inflamáveis líquidos e 
atividades ligadas diretamente ao abastecimento de viaturas com motor de explosão. Nas operações de transporte de inflamáveis líquidos ou gasosos liquefeitos, em quaisquer vasilhames e a granel, são consideradas em condições de periculosidade, exclusão para o transporte em pequenas quantidades, até o limite de 200 (duzentos) litros para os inflamáveis líquidos e 135 (cento e trinta e cinco) quilos para os inflamáveis gasosos liquefeitos. A permanência em área de risco gera direito ao adicional de periculosidade, não sendo necessário para a configuração da periculosidade que o empregado opere a bomba diretamente na movimentação de combustíveis, bastando para a caracterização do trabalho em ambiente perigoso que o trabalhador opere ou trabalhe em área de risco.

\section{NR-17 - Ergonomia}

Esta NR visa proporcionar conforto, segurança e desempenho eficiente aos trabalhadores. Para avaliar a adaptação das condições de trabalho às características psicofisiológicas dos trabalhadores, cabe ao empregador realizar a análise ergonômica do trabalho para asmínimas condições de trabalho, a exemplo de todas as atividades em que os trabalhos devam ser realizados de pé, devem ser colocados assentos para descanso em locais em que possam ser utilizados por todos os trabalhadores durante as pausas. Os equipamentos que compõem um posto de trabalho devem estar adequados às características psicofisiológicas dos trabalhadores e à natureza do trabalho.

As condições ambientais devem estar adequadas às características psicofisiológicas dos trabalhadores e à natureza do trabalho a ser executado. Nos locais de trabalho onde são executadas atividades que exijam solicitação intelectual e atenção constantes, como atendimento ao cliente, fechamento de caixa, é exigido um grau elevado de concentração e de conforto. A iluminaçâo geral deve ser uniformemente distribuída e difusa, de forma a evitar ofuscamento, reflexos incômodos, sombras e contrastes excessivos.

Em atividades que exijam sobrecarga muscular estática ou dinâmica do pescoço, ombros, dorso e membros superiores e inferiores, e a partir da análise ergonômica do trabalho, para efeito de remuneração e vantagens de qualquer espécie deve levar em consideração as repercussões sobre a saúde dos trabalhadores, incluídas pausas para 
descanso. Quanto ao retorno do trabalho, após qualquer tipo de afastamento igual ou superior a 15 (quinze) dias, a exigência de produção deverá permitir um retorno gradativo aos níveis de produção vigentes na época anterior ao afastamento.

\section{NR-20 - Líquidos Combustíveis e Inflamáveis}

Define-se "líquido combustível" aquele que possua ponto de fulgor igual ou superior a $70^{\circ} \mathrm{C}$ (setenta graus centígrados) e inferior a $93,3^{\circ} \mathrm{C}$ (noventa e três graus e três décimos de graus centígrados), considerado líquido combustível da Classe III. Os tanques para armazenagem de líquidos combustíveis serão construídos de aço ou de concreto e devem ter respiradoures de emergência. A distância entre 2 (dois) tanques de armazenamento de líquidos combustíveis não deverá ser inferior a 1,00m (um metro). O espaçamento mínimo entre 2 (dois) tanques de armazenamento de líquidos combustíveis diferentes, ou de armazenamento de qualquer outro combustível, deverá ser de $6,00 \mathrm{~m}$ (seis metros). Todos os tanques de superfície deverão ter dispositivos que liberem pressões internas excessivas, causadas pela exposição à fonte de calor.

É definido "líquido inflamável" como todo aquele que possua ponto de fulgor inferior a $70^{\circ} \mathrm{C}$ (setenta graus centígrados) e pressão de vapor que não exceda $2,8 \mathrm{~kg} / \mathrm{cm} 2$ absoluta a $37,7^{\circ} \mathrm{C}$ (trinta e sete graus e sete décimos de graus centígrados). Quando o líquido inflamável tem o ponto de fulgor abaixo de $37,7^{\circ} \mathrm{C}$ (trinta e sete graus e sete décimos de graus centígrados), se classifica como líquido combustível de Classe I. Se o líquido inflamável tem o ponto de fulgor superior a $37.7^{\circ} \mathrm{C}$ (trinta e sete graus e sete décimos de graus centígrados) e inferior a $70^{\circ} \mathrm{C}$ (setenta graus centígrados), classifica-se como líquido combustível de Classe II.

Já o líquido "instável" ou "líquido reativo" é aquele que em sua forma pura, comercial, como é produzido ou transportado, se polimerize, se decomponha ou se condense, violentamente, ou que se torne auto-reativo sob condições de choque, pressão ou temperatura. Os tanques que armazenam líquidos inflamáveis, instalados enterrados no solo, deverão obedecer aos seguintes distanciamentos mínimos: 1,00m (um metro) de divisas de outras propriedades e 0,30m (trinta centímetros) de alicerces de paredes, 
poços ou porão. Somente poderão ser instalados no interior de edifícios sob a forma de tanques enterrados e equipados com respiradouros de pressão e vácuo ou corta-chamas, localizados de forma que fiquem fora de edificações e no mínimo a 3,50m (três metros e cinqüenta centímetros) de altura do nível do solo. Todos os tanques de superfície deverão ter dispositivos que liberem pressões internas excessivas, causadas pela exposição à fonte de calor.

Para efetuar-se o transvazamento de líquidos inflamáveis de um tanque para outro, ou entre um tanque e um carro-tanque, obrigatoriamente os dois deverão estar aterrados ou ligados ao mesmo potencial elétrico. Deverá existir letreiro com dizeres "Não Fume" e "Inflamável" em todas as vias de acesso ao local de armazenagem. Nos locais de descarga de líquidos inflamáveis, deverá existir fio terra apropriado, para se descarregar a energia estática dos carros transportadores, antes de efetuar a descarga do líquido inflamável. A descarga deve se efetuar com o carro transportador ligado à terra. Todo equipamento elétrico para manusear líquidos inflamáveis deverá ser especial, à prova de explosão.

\section{NR-23 - Proteção Contra Incêndios}

Todas as empresas deverão possuir proteção contra incêndio; saídas suficientes para a rápida retirada do pessoal em serviço, em caso de incêndio; equipamento suficiente para combater o fogo em seu início; e pessoas treinadas no uso correto desses equipamentos.

As saídas deverão ter um número suficiente e dispostas de modo que as pessoas possam abandonar com rapidez e segurança o seu local de trabalho, em caso de emergência. Onde não for possível o acesso imediato às saídas, deverão existir, em caráter permanente e completamente desobstruídos, circulações internas ou corredores de acesso contínuos e seguros. As portas de saída devem ser de batentes ou portas corrediças horizontais, a critério da autoridade competente em segurança do trabalho. As portas verticais, as de enrolar e as giratórias não serão permitidas em comunicações internas. Todas as portas de batente, tanto as de saída como as de comunicações internas, devem abrir no sentido da saída e que não impeçam as vias de passagem. As portas que 
conduzem às escadas devem ser dispostas de maneira a não diminuírem a largura efetiva dessas escadas. As portas de saída devem ser dispostas de maneira a serem visíveis, ficando terminantemente proibido qualquer obstáculo, mesmo ocasional, que entrave o seu acesso ou a sua vista. Em nenhum momento portas de entradas, ou saídas, ou de emergências de um estabelecimento ou local de trabalho, deverá ser fechada a chave, aferrolhada ou presa durante as horas de trabalho. Em hipótese alguma, as portas de emergência deverão ser fechadas pelo lado externo, mesmo fora do horário de trabalho. Todas as escadas, plataformas e patamares deverão ser feitos com materiais incombustíveis e resistentes ao fogo. As caixas de escadas deverão ser providas de portas corta-fogo, fechando-se automaticamente e podendo ser abertas facilmente pelos 2 (dois) lados.

Os exercícios de combate ao fogo deverão ser feitos periodicamente, objetivando que o pessoal grave o significado do sinal de alarme; a evacuação do local se faça em boa ordem; seja evitado qualquer pânico; seja gravadas tarefas e responsabilidades específicas aos empregados e que seja verificado se a sirene de alarme foi ouvida em todas as áreas. Esses planos de exercício de alerta deverão ser preparados como se fossem para um caso real de incêndio.

O fogo pode ser classificado de quatro formas, a saber: Classe A, são materiais de fácil combustão com a propriedade de queimarem em sua superfície e profundidade, e que deixam resíduos, como: tecidos, madeira, papel, fibra, etc.; Classe B, são considerados inflamáveis os produtos que queimem somente em sua superfície, não deixando resíduos, como óleo, graxas, vernizes, tintas, gasolina, etc.; Classe C, quando ocorrem em equipamentos elétricos energizados como motores, transformadores, quadros de distribuição, fios, etc; Classe $\mathrm{D}$, elementos pirofóricos como magnésio, zircônio, titânio.

Em todos os estabelecimentos ou locais de trabalho só devem ser utilizados extintores de incêndio que obedeçam às normas brasileiras ou regulamentos técnicos do Instituto Nacional de Metrologia, Normalização e Qualidade Industrial - INMETRO, garantindo essa exigência pela aposição nos aparelhos de identificação de conformidade 
de órgãos de certificação credenciados por ele. Qualquer estabelecimento, mesmo os dotados de chuveiros automáticos, deverão ser providos de extintores portáteis, a fim de combater o fogo em seu início. Tais aparelhos devem ser apropriados à classe do fogo a extinguir.

Os tipos de extintores portáteis são do tipo "Espuma", utilizado nos fogos de Classe A e B este tipo de extintor deverá ser recarregado anualmente; e do tipo "Químico Seco", para fogos das Classes B e C. As unidades de tipo maior de 60 a $150 \mathrm{~kg}$ deverão ser montadas sobre rodas. Nos incêndios Classe D, será usado o extintor tipo "Químico Seco", porém o pó químico será especial para cada material. O método de abafamento por meio de areia (balde areia) poderá ser usado como variante nos fogos das Classes B e D.

Cada extintor deverá ser inspecionado visualmente a cada mês, examinando-se o seu aspecto externo, os lacres, os manômetros, quando o extintor for do tipo pressurizado, verificando se o bico e válvulas de alívio não estão entupidos. Deverão ter uma etiqueta de identificação presa ao seu bojo, com data em que foi carregado, data para recarga e número de identificação. Essa etiqueta deverá ser protegida convenientemente a fim de evitar que esses dados sejam danificados. Os cilindros dos extintores de pressão injetada deverão ser pesados semestralmente. Se a perda de peso for além de 10\% (dez por cento) do peso original, deverá ser providenciada a sua recarga.

Os extintores deverão ser colocados em locais de fácil visualização e acesso, onde haja menos probabilidade de o fogo bloquear o seu manuseio. Os locais destinados aos extintores devem ser assinalados por um círculo vermelho ou por uma seta larga, vermelha, com bordas amarelas.

\section{NR-26 - Sinalização de Segurança}

Tem por objetivo fixar as cores que devem ser usadas nos locais de trabalho para prevenção de acidentes, identificando os equipamentos de segurança, delimitando áreas, identificando as canalizações empregadas nas indústrias para a condução de líquidos e gases e advertindo contra riscos. Ressalta-se que a utilização de cores não dispensa o 
emprego de outras formas de prevenção de acidentes. O uso dessas cores deverá ser o mais reduzido possível, a fim de não ocasionar distração, confusão e fadiga ao trabalhador.

As cores aqui adotadas serão as seguintes:

- Vermelho - deverá ser usado para distinguir e indicar equipamentos e aparelhos de proteção e combate a incêndio. Não deve ser usado para assinalar perigo nas indústrias; é usado para identificar os extintores e a sua localização; indicações de extintores, visível a distância, dentro da área de uso do extintor, para extinção de incêndio; transporte com equipamentos de combate a incêndio e as portas de saídas de emergência.

- Branco - é usado em: passarelas e corredores de circulação, por meio de faixas; direção e circulação, por meio de sinais; localização e coletores de resíduos; localização de bebedouros; áreas em torno dos equipamentos de socorro de urgência, de combate a incêndio ou outros equipamentos de emergência; áreas destinadas à armazenagem; zonas de segurança;

- Preto - será empregado para indicar as canalizações de inflamáveis e combustíveis de alta viscosidade, a exemplo de óleo lubrificante, asfalto, óleo combustível, alcatrão, piche, dentre outros. Poderá ser usado em substituição ao branco, ou combinado a este, quando condições especiais o exigirem;

- Lilás - deverá ser usado para indicar canalizações que contenham álcalis. As refinarias de petróleo poderão utilizar essa cor para a identificação de lubrificantes;

- Alumínio - será utilizado em canalizações contendo gases liquefeitos, inflamáveis e combustíveis de baixa viscosidade, a exemplo de óleo diesel, gasolina, querosene, etc;

- Marrom - pode ser adotado, a critério da empresa, para identificar qualquer fluído não identificável pelas demais cores.

Considera-se substância perigosa todo material que seja, isoladamente ou não, corrosivo, tóxico, radioativo, oxidante, e que, durante o seu manejo, armazenamento, 
processamento, embalagem, transporte, possa conduzir efeitos prejudiciais sobre trabalhadores, equipamentos, ambiente de trabalho. Símbolos para identificação dos recipientes na movimentação de materiais deverão ser seguidas as normas técnicas sobre simbologia vigentes no país. Todas as instruções dos rótulos deverão ser breves, precisas, redigidas em termos simples e de fácil compreensão. A linguagem deverá ser prática, não se baseando somente nas propriedades inerentes a um produto, mas dirigida de modo a evitar os riscos resultantes do uso, manipulação e armazenagem do produto.

Nos rótulos deverão constar os seguintes tópicos: Nome técnico do produto; palavra de advertência, designando o grau de risco; indicações de risco; medidas preventivas, abrangendo aquelas a serem tomadas; primeiros socorros; informações para médicos, em casos de acidentes; e instruções especiais em caso de fogo, derrame ou vazamento, quando for o caso. As palavras de advertência que devem ser usadas são: "perigo", para indicar substâncias que apresentem alto risco; "cuidado", para risco médio; e "atenção", para risco leve.

\section{Acidentes de Trabalho}

Acidente do trabalho, de acordo com a Lei 8.213 (Art.19), é o que ocorre pelo exercício do trabalho a serviço da empresa ou pelo exercício do trabalho, provocando lesão corporal ou perturbação funcional que cause a morte ou a perda ou redução, permanente ou temporária, da capacidade para o trabalho.

Já o Art. 20 da Lei 8.213, considera como acidente do trabalho: a doença profissional, assim entendida a produzida ou desencadeada pelo exercício do trabalho peculiar a determinada atividade; e doença do trabalho, assim entendida a adquirida ou desencadeada em função de condições especiais em que o trabalho é realizado.

Equiparam-se também ao acidente do trabalho o acidente ligado ao trabalho que, embora não tenha sido a causa única, haja contribuído diretamente para a morte do segurado, para redução ou perda da sua capacidade para o trabalho, ou produzido lesão que exija atenção médica para a sua recuperação; e o acidente sofrido pelo segurado no local e no horário do trabalho, em conseqüência de ato de agressão, sabotagem ou 
terrorismo praticado por terceiro ou companheiro de trabalho; ofensa física intencional, inclusive de terceiro, por motivo de disputa relacionada ao trabalho; ato de imprudência, de negligência ou de imperícia de terceiro ou de companheiro de trabalho; ato de pessoa privada do uso da razão; desabamento, inundação, incêndio e outros casos fortuitos ou decorrentes de força maior; a doença proveniente de contaminação acidental do empregado no exercício de sua atividade; e o acidente sofrido pelo segurado ainda que fora do local e horário de trabalho, na execução de ordem ou na realização de serviço sob a autoridade da empresa, na prestação espontânea de qualquer serviço à empresa para lhe evitar prejuízo ou proporcionar proveito, em viagem a serviço da empresa, ou no percurso da residência para o local de trabalho ou deste para aquela, qualquer que seja o meio de locomoção, inclusive veículo de propriedade do segurado.

As maiores causas de acidente de trabalho são: a prática de ato inseguro, a prática de condições inseguras e os fatores pessoais. A causa de ocorrer à prática de ato inseguro esta ligada ao comportamento humano no seu ambiente de trabalho, tais como: a curiosidade, distração, teimosia, pressa, entre outros atos que podem causar por um motivo ou outro um acidente de trabalho. No que se diz respeito às condições inseguras essa causa está ligada à falta de manutenção em máquinas e equipamentos e a segurança oferecida pela empresa são alguns dos fatores que podem levar a ocorrência de acidentes de trabalho. Outra prática que pode levar a um acidente de trabalho é o fator pessoal, pois está ligado ao estado físico, emocional, mental e até mesmo ao social, influenciando de maneira negativa no trabalho e podendo levar o individuo a trazer condições de risco para a empresa na qual trabalha.

\section{Resultado da pesquisa: as condições de segurança na Empresa $X$}

A partir do referencial acima foram analisadas as condições de segurança em que se encontram os funcionários de base da Empresa X, no Município de Anastácio/MS, chamando a atenção dos empregadores em se adequar às condições exigidas pela Lei $\mathrm{n}^{\circ}$ 6.514 da CLT. 
Fori aplicado um questonário aos 10 (dez) funcionários de base, entendidos como aqueles que abastecem, trocam óleo de veículos, lubrificam, lavam esses veículos e descarregam caminhão de combustíveis. As primeiras informações extraídas versam sobre o perfil destes funcionários, sendo todos do gênero mascullno, com uma faixa etária de 30 (trinta) anos, dos quais 5 (cinco) disseram possuir o Ensino Médio completo.

O questionário foi elaborado com $10(\mathrm{dez})$ perguntas, sendo todas a respeito das condições de trabalho. A primeira delas foi elaborada para saber se a carga horária de trabalho está dentro dos limites estabelecidos pelo art. 58 da CLT, ou seja, se a jornada de trabalho é de 44 (quarenta e quatro) horas semanais. Observou-se que a empresa esta dentro dos padrões legais, visto que os 10 (dez) entrevistados responderam trabalhar 8 (oito) horas diárias.

A segunda questão diz respeito às condições ambientais no trabalho, onde 6 (seis) dos 10 (dez) funcionários atestaram correr um grau médio com relação ao indíce de periculosidade na empresa, sendo que os demais alegaram sentir-se inseguros na execução das tarefas diárias, o que nos demonstra um grave problema interno na política da empresa e na execução dos trabalhos, além da instatisfação dos empregados que se consideram em risco permanente.

As questões 3, 4, 5 e 6 foram voltadas ao bem estar físico, a saúde dos funcionários, onde foram questionados se sentem dores de cabeça e 8 (oito) responderam sentir as vezes e 2 (dois) não sentem, já quando questionados a respeito de sentir dores em algum dos membros como: pernas, braços ou articulações, 8 (oito) disseram não sentir nenhum tipo de dor com relação a seus membros ou articulações.

Quanto a sentir mal estar, enjôo, fadiga, cansaço ou tontura, 8 (oito) responderam não sentir nenhum tipo de mal estar e $100 \%$ disseram não sofrer nenhum tipo de problemas respiratórios como alergias, tosses ou espirros, o que reflete as consequências da exposição aos gases toxicos provenientes de suas funções no trabalho e que deveriam ter a divida atenção por parte dos empregadores. 
Foi levantada também a utilização de equipamentos de proteção individual por parte destes funcionários. Surpreendentemente, constatou-se que 6 (seis) funcionários não utilizam equipamentos de proteção individual, embora atestem-se ameaçados pelo trabalho.

Interessante resaltar que 5 (cinco) dos 10 (dez) funcionários responderam quando perguntados quais os equipamentos de proteção que mais utilizam, relataram que o conjunto formado por calça e blusão é o equipamento de proteção mais usado.

A contradição relacionada a pergunta anterior nas respostas obtidas caracteriza o desconhecimento por parte dos entrevistados quanto ao que seria este equipamento de proteção dentro da empresa. Todavia, ao serem listados os EPIs por meio de alternativas, responderam afirmativamente que utilizam.

Quanto ao uso correto dos extintores de incêndio, 9 (nove) responderam que sabem utilizar corretamente e apenas um disse não saber manuseá-lo, o que constata falta gravíssima para função que ocupa, pois não sabe se defender e nem zelar pelos clientes da empresa, expondo todos à riscos. Verificou-se que o funcionário não recebeu o devido treinamento porque era contratado ha pouco tempo e o treinamento de segurança é dado um vez ao ano. Entretanto, cabe a um responsável dar o treinamento adequado aos funcionários ativos para que possam desenpenhar corretamente suas funções, principalmente no que tango ao bem estar e segurança coletiva, utilizando seus conhecimentos e técnicas desenvolvidas no combate a incêndios para se proteger salvaguardar as pessoas a sua volta de uma situação de risco eminente.

Finalizando o questionário, foi indagado aos funcionários se consideram importante o uso dos equipamentos de proteção e $100 \%$ responderam que sim, que consideram muito importante. Dessa maneira, o questionário aplicado possibilitou a análise das condições de trabalho dos empregados da empresa investigada, podendo assim, comparar a prática dos trabalhos realizados com as Normas que regulamentam Segurança do Trabalho. É Interessante ressaltar a constatação das condições adequadas as quais estão submetidos os funcionários de base da empresa investigada, pois, os mesmos 
de certa forma estão enquadrados dentro do que rege a Lei e as Normas que regem a segurança do trabalho.

\section{Atividades desenvolvidas pelos funcionários de base da Empresa $\mathrm{X}$}

Os funcionários de base da Empresa $\mathrm{X}$ desenvolvem basicamente 5 (cinco) atividades cotidianamente, a saber: abastecimento de veículos; lavagem de veículos; lubrificação; troca de óleo; e descarregamento de combustíveis, as quais apresentamos a seguir.

\section{Abastecimento de veículos}

A empresa possui 8 (oito) bombas de combustíveis, sendo que 3 (três) são de gasolina; 1 (um) de álcool e 4 (quatro) de Diesel. Os funcionários são divididos por turnos de trabalhos diferenciados.

No abastecimento de veículos ocorre o seguinte processo: três funcionários cuidam da parte de abastecimento dos veículos. O frentista deve se atentar qual o tipo de veículo que irá abastecer, tomando cuidado para não abastece-lo com o combustível errado, bem como qual a preferência do cliente quanto a quantidade de combustível adquirida. Após o abastecimento do veículo o frentista deve perguntar ao cliente se gostaria que fosse conferida a frente do veículo, a fim de verificar o nível do óleo, do fluído de freios, óleo da direção, reservatórios de água do limpador de pára-brisas e averiguar também se o cliente gostaria que fossem lavados os pára-brisas do veículo, calibrar os pneus se necessário, posteriormente agradecendo o cliente pela preferência. No ato de abastecer o veículo o mesmo deve pedir para que o cliente saia do veículo, observar se há algum tipo de material que possa vir ocasionar um princípio de incêndio, a exemplo de cigarros acesos.

Os funcionários de base da Empresa $\mathrm{X}$ utilizam diariamente o uniforme, cremes e calçados, o que não impede o contato direto com substâncias químicas e tóxicas. Como os frentistas têm aproximação com clientes, a utilização de máscaras de proteção contra a 
inalação de gases tóxicos não é usual, ocasionando sérios riscos que deve ser estudado a fim de buscar um mecanismo ou até um meio para que os frentistas não inalem os gases tóxicos dos combustíveis. Geralmente, no ato do abastecimento, eles procuram evitar a inalação desses gases, desviando seu rosto para o lado contrário do vento ou longe da entrada do tanque de combustível do veículo, pois, dentro do tanque os gases atuam de forma bem mais concentrada e sua eliminação é imediata com a abertura do tanque.

De acordo com as Normas Regulamentadoras de Segurança e Medicina do Trabalho, NR6 que trata do uso de EPIs, cabe ao empregador adquirir os equipamentos adequados a cada tipo de atividade e exigir que seus funcionários os utilizem da maneira correta. O uso de máscaras evitando a inalação de gases químicos e tóxicos, o uso de luvas protege o contato da pele com produtos químicos e evita que o trabalhador se contamine com algum tipo de substância química no ato de lavar algum tipo de veículo na mistura dessas substâncias, o que não ocorre na empresa estudada.

\section{Lavagem}

A empresa possui um lava-jato. Os donos dos veículos geralmente são clientes fixos do posto e por isso não pagam pelo serviço. O frentista responsável pela lavagem do veículo o leva até o local apropriado, coloca-o na rampa e inicia a lavagem com água em forte pressão, utilizando um sabão conhecido por "verdão", além de "solopan", produto químico extra forte que possibilita a melhor remoção de resíduos. Em seguida, enxágua o veículo e finaliza com a secagem por intermédio de compressor de ar e aspiração interna.

No que se diz respeito ao contato com substâncias tóxicas, o frentista precisa manipular e misturar os produtos que, na maioria das vezes, são comprados em grande quantidades de até 2001. O contato com produto químico também se dá através do ato da lavagem, pois o ar e o vento acabam empurrando gotículas do produto no funcionário, contaminando-o e ocasionando possíveis irritações na pele e ardência nos olhos. Por isso, em lava-jatos deve haver fiscalização intensa, visto que os frentistas precisam usar óculos de proteção para os olhos e máscaras para que não inalem os produtos químicos. 


\section{Lubrificação}

A lubrificação dos veículos é feita em uma rampa apropriada para caminhonetes, caminhões e carretas. O processo de lubrificação é bastante simples, porém o frentista deve tomar alguns cuidados, pois o veículo deve de estar ligado para que ocorra a movimentação das cruzetas a serem engraxadas, o que pode vir a ocasionar um acidente de trabalho.

\section{Troca de óleo}

A troca de óleo deve ser feita por um frentista treinado e capacitado para a função, pois é preciso cerco conhecimento a respeito dos diferentes tipos de óleo, informando-se com o cliente sobre a viscosidade do óleo usado no veículo. Também, deve saber se o cliente fará uma troca completa, incluindo os filtros de óleo e ar, além de verificar o nível do óleo de câmbio e diferencial. O responsável por esses procedimentos dever se atentar para não comprometer a vida utíl do motor, podendo o bujão do cárter ficar solto ou frouxo ou até mesmo o filtro de combustível mal colocado, visto que quaisquer danos referentes ao serviço são de responsabilidade da empresa.

\section{Descarregamento de combustíveis}

O descarregamento de combustível no posto é a mais complexa atividade no que se refere a segurança pessoal e coletiva. $\mathrm{O}$ frentista encarregado pelo descarregamento de combustíveis deve saber trabalhar em equipe, pois precisa da ajuda do motorista e de seus colegas de trabalho.

No momento em que o caminhão-tanque adentra o recinto, os funcionários responsáveis deverão estar atentos a qual combustível irá descarrregar no tanque do posto. Feito isso o frentista deve juntamente com o motorista do caminhão fazer o processo de preparação para descarga, isolando a área com cones e placas de sinalização para que as pessoas não se aproximem e não fumem. Posteriormente verifica-se o caminhão para se certificar de que não há nenhuma alteração nos lacres de segurança. Em seguida, é preciso subir no caminhão para tirar o gás existente do tanque, abrindo a válvula e 
verificando se o combustível está no limite da seta que indica a quantidade exata, de acordo com a nota de compra. Após esta verificação, abre-se o tanque no qual é descarregado o combustível e se faz o isolamento térmico por meio de um fio terra para iniciar-se o descarregamento. É coletada uma amostra para análise da qualidade do produto. Por fim, deve-se estar atento para que ninguém se aproxime sem a devida autorização e utilize algum istrumento que possa provocar incêndio. Após tomados todos esses cuidados é feito o processo de escorrer o caminhão para que não fique grande quantidade de resíduos no tanque.

\section{Considerações finais}

As empresas, em sentido amplo, possuem inúmeras tarefas diárias que podem causar riscos a saúde e integridade do trabalhador. A falta de um setor de segurança especializado pode ocasionar falhas e pouca visibilidade interna, deixando os funcionários sem as devidas instruções de segurança para suas funções básicas. $\mathrm{O}$ treinamento, a integração e a conscientização de uma cultura empresarial voltada para a segurança do trabalho é uma importante tarefa que deve ser iniciada dentro da empresa, por intermédio de seus gestores e representantes, para depois ser trabalhada com as equipes operacionais, incentivando assim, a colaboração de todos os níveis da organização e minimizando riscos de possíveis acidentes causados pela falta de segurança do trabalho.

O risco de vida e o contato e inalação de produtos químicos são riscos em que os trabalhadores da empresa investigada estão expostos diariamente na execução de suas tarefas. Para a adequação das atividades de abastecimento de veículos, lavagem, lubrificação, troca de óleo e descarregamento de combustíveis há a necessidade da implantação de algumas Normas de Segurança e Medicina do Trabalho, cabendo ao empregador adotá-las e fiscalizá-las. O primeiro passo é o de conscientizar o gestor da importância da segurança no trabalho, sabendo dos riscos e dos prejuízos que pode vir a sofrer caso aconteça algum acidente em sua empresa.

Revista Administração em Diálogo ISSN 2178-0080 
A insalubridade é devida aos empregados que lavam veículos, trocam óleo e lubrificam, na razão de grau médio, correspondente, assim em $20 \%$ de adicional sobre o salário mínimo. Ocorre que em alguns trabalhos, os empregados estão sujeitos tanto a insalubridade quanto à periculosidade: é o caso dos frentistas. Neste caso poderão optar por um ou outro adicional, não lhes são devidos os dois adicionais, normalmente, a escolha é para o adicional é de $30 \%$, porque é calculado sobre o salário base e não sobre o salário mínimo, como o de insalubridade. $\mathrm{O}$ trabalho realizado perigosamente, em razão dos produtos inflamáveis ou explosivos terá o adicional de $30 \%$ integralmente, mesmo que trabalhador intermitentemente, não disponha sobre a proporcionalidade ao pagamento do adicional de periculosidade.

No que se diz respeito a NR-16, o transporte de inflamáveis líquidos exige uma série de cuidados desde o carregamento do caminhão até a venda final para o veículo, passando por cuidados de manejos para se evitar qualquer acidente. Com relação as NRs que tratam da parte de segurança de combate ao risco eminente, como por exemplo, a NR-23, a empresa investigada tem todos os sistemas e meios de segurança no combate a incêndios. Em cada pilar do posto se localiza um extintor e em cada sala existe um extintor adequado e inspecionado a cada mês, colocados em locais de fácil visualização e acesso. Os locais onde estão os extintores estão assinalados por um círculo vermelho ou uma seta larga vermelha, com bordas amarelas. A NR-26 que trata da Sinalização de Segurança que é muito usada em postos de combustíveis para indicar se uma área estiver interditada, para sinalização dos extintores de incêndio quanto a sua localização e composição, para sinalizar se naquela área corre algum tipo de perigo ou risco.

O abastecimento de veículos é uma das atividades mais rotineiras e freqüentes dos funcionários de base da Empresa $\mathrm{X}$, exigindo bom preparo por parte dos funcionários e atenção especial à sua saúde, pois, devido ao constante desgaste e esforço físico, precisam se atentar aos problemas ocasionados pelo trabalho de ficar muito tempo em pé e expostos a produtos químicos e tóxicos. Para minimizar os riscos, recomenda-se a implantação da NR-05 que trata da Comissão Interna de Prevenção de Acidentes (CIPA). Outra importante NR a ser adotada pela Empresa X para o auxilio na prevenção 
de acidentes de trabalho é o uso diário no desempenho das atividades de Equipamentos Individuais de Proteção (EPI) - NR-06, que são indispensáveis, em atividades que ofereçam riscos a saúde do trabalhador, juntamente com o Programa de Prevenção de Riscos Ambientais - NR-09, devido ao trabalho diário a céu aberto e com a presença de ruídos, poeira, exposição ao sol, entre outros fatores de riscos que precisam ser adequados para não prejudicar a integridade física dos trabalhadores.

Pode-se considerar que a Empresa $\mathrm{X}$ investigada está de certo modo de acordo com a a Lei e com as Normas de Segurança do Trabalho, devendo apenas mudar o seu modo de treinamento com os funcionários. Esse treinamento deve ser dado no momento em que o funcionário adentra a empresa e começa a trabalhar nela e não esperar pelo treinamento do Corpo de Bombeiros que é ministrado uma vez por ano. A operação inadequada de equipamentos em áreas de risco, com armazenagem de combustíveis altamente inflamáveis expõe não somente os trabalhadores mas todo o entorno e os clientes a danos materiais e ambientais, além do risco de morte.

A aplicações da Lei e das Normas Regulamentadoras são pontos fundamentais na prevenção de acidentes do trabalho, pois norteiam os empregadores a respeito das formas seguras de realização das tarefas diárias. Outro fator positivo é a conquista do respeito e da confiança dos empregados que se sentem muito mais seguros e valorizados pela empresa. Portanto, a empresa que investe e se preocupa com a segurança dos seus trabalhadores, ganha a confiança do empragado e da sociedade, refletindo no aumento de sua produtividade pela satisfação de seus empregados, bem como no aumento da comercialização dos seus produtos e serviços.

\section{Referências bibliográficas}

ACEVEDO, C. \& NOHARA, J. J. Monografia no curso de Administração. São Paulo: Atlas, 2004. 150 p.;

BARBOSA FILHO, A N. Segurança do Trabalho \& Gestão Ambiental. São Paulo: Atlas, 2001. 188 p.;

BRASIL. Constituição Federal. 33 ed. São Paulo: Saraiva, 2006, 230 p.; 
Ministério do Trabalho e Emprego. Segurança e Saúde no Trabalho.

Disponível em: http://www.mte.gov.br. Acesso em: 01 fev. 2008;

FERREIRA, A B de H. Mini Aurélio Século XXI Escolar. 4 ed. rev. ampl.. Rio de Janeiro: Nova Fronteira, 2001;

RICHARDSON, R. J. (et al). Pesquisa social: método e técnicas. 3 ed. rev. ampl. São Paulo: Atlas, 1999. 176 p.;

SEGURANÇA E MEDICINA DO TRABALHO. Manuais de Legislação Atlas. 59 ed. São Paulo: Atlas, 2006. 375 p. 